\title{
THE VIEW OF PATIENTS WITH CHORONIC OBSTRUCTIVE PULMONARY DISEASE (COPD) ON COMPLEMENTARY AND ALTERNATIVE MEDICINE (CAM) IN EASTERN TURKEY
}

\author{
${ }^{1}$ Zümrüt Akgün Şahin and ${ }^{2}$ Mutlu Şahin \\ ${ }^{1}$ Kars Health School, Kafkas University, Kars, Turkey \\ ${ }^{2}$ Department of Internal Medicine, Kars Goverment Hospital, Kars, Turkey. \\ *E-mail: zumrut8136@hotmail.com, drmsahin 81@hotmail.com
}

\begin{abstract}
The purpose of this study was to examine the frequency of complementary and alternative medicine usage in Chronic Obstructive Pulmonary Disease (COPD) patients living in the eastern part of Turkey. In this study a descriptive design was used. The study was conducted with 216 patients who were present at the clinic. Data were gathered by the researchers in a comfortable setting through questionnaire method using the data collection form developed by the researcher. Individualised questionnaire-based interviews were also conducted among the 216 adult patients. The questionnaire included demographic information, clinical information, use of conventional therapies, and complementary and alternative therapy. According to the findings obtained in this research, the frequency of CAM use among Turkish COPD patients (72.1\%) was close to the highest levels reported in the literature.
\end{abstract}

Key words: Complementary and alternative therapy, COPD, Turkey

\section{Introduction}

Throughout the world, patients with chronic diseases tend to be high utilisers of health care resources and/or the health care system. Complementary and alternative medicine (CAM) has been used for decades in the management of chronic diseases like cancer, diabetes, cardiovascular diseases and stroke (Mao et al. 2011; Broom et al. 2010; Ogbera et al. 2010; Khalaf \& Whitford 2010; Decker et al. 2007; Yeh et al. 2006; Zick et al. 2005; Shah et al. 2008). Chronic obstructive pulmonary disease is one of a number of common disorders for which there is a varied literature in support of CAM therapies. Chronic obstructive pulmonary disease (COPD) is a respiratory disorder in that it is chronic and characterised with decreased airflow. COPD has characteristics such as the signs of coughing and wheezing. It has two distinct conditions in terms of disease onset: frequency of symptoms and reversibility of airway obstruction. Unsatisfactory treatment outcomes from conventional drugs and adverse effects associated with several classes of drugs, such as steroids and theophylline, contribute substantially to the increasing popularity of CAM and, in particular, herbal medicine (Celli et al. 2004). National Center for Complementary and Alternative Medicine (NCCAM) defines CAM as a group of diverse medical and health care systems, practices and products that are not generally considered part of conventional medicine (www.cdc.gov/nchs/data/ad/ad343.pdf.).

Despite all the current developments in pharmacological treatments, the use of CAM methods continues to show a remarkable increase, both in developing and in developed countries (Arguder et al. 2009). In the USA, a study conducted at the national level with a large sampling indicated that the usage rate of alternative therapies had reached $42.1 \%$ in 1997 , up from 33.8\% in 1990 (Eisenberg et al. 1998). Although 40\% of the general USA population was using CAM, in Turkey this percentage was reported at $80.2 \%$ of healthy individuals (Ernst 1999; Oguz \& Pinar 2000). The prevalence of CAM use in Turkish patients with chronic diseases is notably higher than in other typical populations (Kurt et al. 2004). The prevalence of CAM use among adult patients ranged between 4-79\% (for example, $41-62 \%$ in the USA, 59\% in the UK, $26.5 \%$ in Germany, 27.2\% in Singapore) (Barnes et al. 2004; Slader et al. 2006). Although many reported studies are addressed to CAM practices in the world (Blanc et al. 1997; Janson et al. 1997; Ernst 1998; Ng et al. 2003), there are limited studies of CAM usage among CAPD patients in Turkey (Arguder et al. 2009; Kurt et al. 2004; Orhan \& Sekerel 2002; Abadoglu et al. 2008; Babayigit et al. 2008; Ediger et al. 2008; Erci 2007).

The aims of the present study were to identify the following:

1. CAM usage frequency in Choronic Obstructive Pulmonary Disease (COPD) patients living in the eastern part of Turkey;

2. the most frequently used CAM method and demographic and disease-associated factors that affect CAM use.

\section{Materials and Methods}

Sample

This study was a descriptive survey conducted at a general hospital in the city of Kars, at the eastern part of Turkey.

The study was conducted with 216 patients who were present at the clinic. The patients were $\geq 18$ years old, had no psychiatric disorder and communication problems, were conscious, and consented to participate in the study. 


\section{Research design}

In this study a descriptive design was used.

\section{Data collection form}

Data were gathered by the researchers in a comfortable setting through questionnaire method using the data collection form developed by the researcher. The data collection form consisted of two parts. The first part sougt to elicit information on the sociodemographic and illness-related details on the patients, such as age, sex, marital status, educational status, economic status, how long they have or have been using CAM, whether the doctor or the nurse uses knowledge of CAM, what the doctor or the nurse think about using CAM, and why they prefer CAM usage were questioned. The second part of the administered questionnaire questioned which of the CAM methods were used by the patients.

\section{Ethical issues}

Before the application of data collection tools, patients were informed about the objective of the research and their informed consent was received on their voluntary participation in the research. Patients who accepted to participate in the research were given the questions; approximately 30-40 minutes were allocated to each patient for the completion of the questionnaire. Permission for conducting this study was obtained from the management of the hospital. Participants were informed of the purpose and procedure of the study. Written consents were obtained from the participants.

\section{Statistical analysis}

The research data were analysed with regard to number, percentage, arithmetic mean and chi-square, using the SPSS 15.0 program (SPSS Inc., Chicago, IL, USA). Chi-square analyses were conducted among the groups to test for statistically significant differences. In the analysis of data, the CAM use status of patients was taken as a dependent variable, and the independent variables were based on their demographic and disease characteristics. The statistically significant level was set at $\mathrm{p}<0.05$.

\section{Results}

The results show a total of 216 patients $64.2 \%$ male. The mean age of the sample was $57.9 \pm 16.8$ years. More than half of the participants were married (62.2\%); the highest educational level of participants were illiterate (41.7\%), and their perceived income level was low (57.4\%). Illness duration was $12.24 \pm 5.79$ years. Number of symptoms experienced by patients was $9.73 \pm 4.45$. The percentage of patients who used their medication regularly was $96.7 \%$, and $90.8 \%$ of the cases used at least one CAM method. $62.0 \%$ of patients included in the study have used CAM treatment for 14 years and over; $76.9 \%$ have known that their doctor or nurse has used CAM treatment; $41.7 \%$ have not interfered with their doctor or nurse about usage of CAM treatment; and $45.4 \%$ have used CAM treatment since they became aware that it is useful.

The CAM methods used by the patients are $56.7 \%$ herbal medicine; $78.5 \%$ foods; $45.8 \%$ deep breating; $65.6 \%$ use of herbal tea; $47.7 \%$ application of vapour; $45.2 \%$ receiving massage; $47.3 \%$ receiving exercise; $60.2 \%$ entering the asthma cave;, $52.1 \%$ taking vitamin and mineral pills.

Patients report that they use herbal medicine and foods for reducing dyspnoea, mucus secretion, and deep breathing. They use herbal tea for reducing mucus secretion, for comfortable breathing; vitamin and mineral pills for improving health, deep breathing. Exercise and massage are used for mucus secretion, relaxing, and asthma cave use treatment of COPD (Table 1).

The percentage distribution of patients who use different methods include the following: patients who use mallow tea $(39.5 \%)$, nigella $(43.6 \%)$, honey $(43.3 \%)$, mint tea (48.6\%), sage tea $(45.2 \%)$, rosehip $(49.8 \%)$, thyme tea $(32.5 \%)$, lemon balm tea $(45.2 \%)$ and gren tea $(46.6 \%)$ (The cases use more than one CAM method).

There is no statistically significant difference between patients who use and who do not use CAM methods regarding age, gender, marital status, educational status and income level $(\mathrm{p}>0.05)$.

\section{Discussion}

In people with chronic diseases like COPD, CAM usage might be prevalent, and the methods used might vary according to geographical areas and culture (Helms 2006). In this study, which assesses the CAM methods practised among patients in eastern Turkey, we determined that $72.1 \%$ of patients use at least one CAM method. Akinci et al., Abadoğlu et al., Arguer et al. reported that CAM methods are common with COPD patients in Turkey, supporting our results (Akinci et al., 2011; Arguder et al. 2009; Abadoglu et al. 2008). Many factors, such as the perceived level of the seriousness of the disease, the symptoms causing discomfort to the patients, the culture surrounding the patient and the accessibility and availability of the alternative treatments, affect the rate of CAM use (Fouladbakhsh \& Stommel 2007).

In Turkey, a country with strong and rich cultural traditions, it is not surprising that CAM use has a high prevalence. We determined that patients use each CAM method for different purposes, such as,treatment of COPD, relaxing, improving 
health. Ng et al., Celli et al., George et al., reported that CAM usage is higher in patients with worse breathing functions (Celli et al. 2004; $\mathrm{Ng}$ et al. 2003; George et al. 2004). Similarly, Akinci et al. found that exacerbations, hospitalisation and severe symptoms were related to CAM usage, and patients who experienced more exacerbations, who were more frequently hospitalised and who had more severe symptoms reported higher CAM usage (Akinci et al. 2011). COPD patients use CAM methods for eliminating breathing problems. Several herbal remedies with the potential to improve pulmonary function, to relieve symptoms or to reduce exacerbation severity and frequency were identified in the treatment of COPD. However, the effectiveness of herbal remedies for treating COPD has not been established (Abadoglu et al. 2008). Similarly, in our study, the results showed that COPD patients evaluated the efficacy of CAM as useful. In this study too, patients used their medications regularly. $96.7 \%$ and $90.8 \%$ of the cases used at least one CAM method. Akinci et al., Slader et al. determined that a large portion of patients used CAM methods (Slader et al. 2006, Akinci et al. 2011). 62.0\% of patients included in the study have used CAM treatment for 14 years and over; $76.9 \%$ has known that their doctor or nurse has used CAM treatment; $41.7 \%$ has not interfered with their doctor or nurse over usage of CAM treatment; and $45.4 \%$ have used CAM treatment since they come to know that it is useful (see Table 2). Similarly, Abadoglu et al., Mazur et al., Braganza et al., Arguder et al. and Akinci et al., Orhan et al., George et al., Singer et al. reported that patients use some of the CAM without any recommendation; some with the suggestions of friends or relatives, and some with the health professionals' recommendations. Studies report that patients gather information from various sources such as friends, relatives, the media and physicians (Arguder et al. 2009; Orhan \& Sekerel 2002; Abadoglu et al. 2008; Akinci et al. 2011; Fouladbakhsh \& Stommel 2007; George et al. 2004; Mazur et al. 2001; Braganza et al. 2003, Singer et al. 2007).

Table 1 Demographic characteristics of patients using CAM Treatment

\begin{tabular}{l|c|c}
\hline Features & N & \% \\
\hline Gender & 138 & 64.2 \\
Female & 68 & 35.8 \\
Male & & \\
Educational Status & 41.7 \\
Illiterate & 26 & 12.0 \\
Literate & 72 & 33.3 \\
primary education & 28 & 13.0 \\
High School and higher & 138 & 62.2 \\
Marital Status & 78 & 37.8 \\
Married & & \\
Single & 124 & 57.4 \\
Income Level & 38 & 17.6 \\
Income is less than expense & 54 & 25.0 \\
Income equals to expense & $\mathbf{2 1 6}$ & $\mathbf{1 0 0}$ \\
Income is more than expense & & \\
\hline Total & & \\
\hline
\end{tabular}

Table 2: CAM Usage of Health Professionals

\begin{tabular}{|c|c|c|}
\hline $\begin{array}{l}\text { How long have you used CAM? } \\
1-6 \text { years } \\
7-13 \text { years } \\
\geq 14 \text { years }\end{array}$ & $\begin{array}{l}44 \\
38 \\
134\end{array}$ & $\begin{array}{l}20.4 \\
17.6 \\
62.0\end{array}$ \\
\hline $\begin{array}{l}\text { Does doctor or nurse use knowledge of CAM? } \\
\text { Yes } \\
\text { No }\end{array}$ & $\begin{array}{r}186 \\
30\end{array}$ & $\begin{array}{l}76.9 \\
23.1\end{array}$ \\
\hline $\begin{array}{l}\text { What is the doctor or nurse thinking about using CAM? } \\
\text { Does not interfere } \\
\text { Does not advise } \\
\text { Suggest } \\
\text { Does not know }\end{array}$ & $\begin{array}{l}90 \\
38 \\
12 \\
76\end{array}$ & $\begin{array}{l}41.7 \\
17.6 \\
5.6 \\
35.2\end{array}$ \\
\hline $\begin{array}{l}\text { Why do you prefer CAM? } \\
\text { I do not trust drug therapy } \\
\text { My environment } \\
\text { I believe that it is useful } \\
\text { Other }\end{array}$ & $\begin{array}{l}40 \\
40 \\
98 \\
16\end{array}$ & $\begin{array}{l}18.5 \\
18.5 \\
45.4 \\
7.4\end{array}$ \\
\hline TOTAL & 216 & 100 \\
\hline
\end{tabular}


The most commonly used CAM methods by the patients include $56.7 \%$ herbal medicine, $45.8 \%$ foods, $78.5 \%$ deep breating, $65.6 \%$ using herbal tea, $47.7 \%$ appling vapour, $45.2 \%$ receiving massage, $47.3 \%$ receiving exercise, $60.2 \%$ entering the asthma cave, $52.1 \%$ taking vitamin and mineral pills. Slader et al., Sidora-Arcoleo et al., Akinci et al. reported that among the various CAM methods herbal products, breathing techniques, prayer and massage, appling vapour, massage, herbal products are the most common CAM methods used by COPD patients (Slader et al. 2006; Akinci et al. 2011; SidoraArcoleo et al. 2007). Two studies earlier conducted in Turkey, which support our results, reported that the most popular CAM methods were herbal remedies in COPD patients (Arguder et al. 2009; Abadoglu et al. 2008). We determined in our study the percentage of patients who use the following herbal remeies to include patients who use mallow tea (39.5\%), nigella (43.6\%), honey $(43.3 \%)$, mint tea $(48.6 \%)$, sage tea $(45.2 \%)$, rosehip $(49.8 \%)$, thyme tea $(32.5 \%)$, lemon balm tea $(45.2 \%)$ and gren tea $(46.6 \%)$. Similar to our findings, it has been reported that herbal products are commonly used CAM methods in Turkey, and these are consumed in form of infusions or herbal tea (Kav 2009; Tarhan et al. 2009; Yildirim et al. 2006; Tas et al. 2005).

The present study also showed that herbal therapy was the most often used form and that the most commonly preferred/used herbals were lime, sage, green tea, chamomile and linseed. In the present study, nutrition and vitamin supplementation and animal-derived products were tested by many patients during the course of their ailment. Among these were trials of drinking Nigella sativa in honey, radish or onion/garlic mixtures, or mixtures made with olive oil and quail eggs (Abadoglu et al. 2008; Fouladbakhsh et al. 2007; Ziment 2003). We found that characteristics such as demographics and disease severity did not influence the use of CAM. The present study also shows that no differences exist between the demographics of patients using and those not using CAM, and these results are in agreement with several other studies reported in the literature (Huntley \& Ernst 2000).

\section{Conclusion}

According to the findings obtained in this research, the frequency of CAM use among Turkish COPD patients $(72.1 \%)$ was close to the highest levels reported in the literature. The COPD patients were found to use CAM methods more frequently. The most frequently used CAM methods were herbal treatments. The duration of doctor diagnosis, hospitalisations, and education on diseases has a higher impact on CAM use in COPD patients.

\section{References}

1. Abadoglu, O., Cakmak, E., Kuzucu., D.S. (2008). The view of patients with asthma or chronic obstructive pulmonary disease (COPD) on complementary and alternative medicine. The Journal of Allergy and Clinical Immunology 36: 21-25.

2. Advance Data, From Vital and Health Statics. Available at: http://www.cdc.gov/nchs/data/ad/ad343.pdf.

3. Akinci, C.A., Zengin, N., Yildiz, H., Sener, E., Gunaydin., B. (2011). The complementary and alternative medicine use among asthma and chronic obstructive pulmonary disease patients in the southern region of Turkey. International Journal of Nursing Practice 17: 571-582.

4. Arguder, E., Bavbek, S., Sen, E., Köse, K., Keskin, O., Saryal, S., Misirligil, Z. (2009). Is there any difference in the use of complementary and alternative therapies in patients asthma and COPD? A crosssectional survey. The Journal of Asthma 46: 252-258.

5. Babayigit, A., Olmez, D., Karaman, O., Uzuner, N. (2008). Complementary and alternative medicine use in Turkish children with bronchial asthma. Journal of Alternative Complementary Medicine 14: 797-799.

6. Barnes, P.M., Powell-Griner, E., McFann, K., Nahin, R.L. (2004). Complementary and alternative medicine use among adults: United States.

7. Blanc, P.D., Ware, G.K., Katz, P.P., Smith, S., Yelin, E.H. (1997). Use of herbal products, coffee or black tea and over-the counter medications as self-treatments among adults with asthma. The Journal of Allergy and Clinical Immunology 100: 789-791.

8. Braganza, S., Ozuah, P.O., Sharif, I. (2003). The use of complementary therapies in inner-city asthmatic children. Journal of Asthma 40: 823-827.

9. Broom, A., Wijewardena, K., Sibbritt, D., Adams, J., Nayar, K.R. (2010). The use of traditional, complementary and alternative medicine in Sri Lankan cancer care: Results from a survey of 500 cancer patients. Public Health 124: 232-237. 


\section{http://dx.doi.org/10.4314/ajtcam.v10i4.19}

10. Celli, B.R., MacNee, W. (2004). Standards for the diagnosis and treatment of patients with COPD: A summary of the ATS/ERS position paper. The European Respiratory Journal 23: 932-946.

11. Decker, C., Huddleston, J., Kosiborod, M. (2007). Self-reported use of complementary and alternative medicine in patients with previous acute coronary syndrome. The American Journal of Cardiology 99: 930-933.

12. $\quad$ Eisenberg, D.M., Davis, R.B., Ettner, S.L., Apel, S., Wilkey, S., Van Ompay, M., Kesler, R.C. (1998). Trends in alternative medicine use in the United States, 1990-1997: results of a follow-up national survey. The Journal of American Medical Assocation 20: 1569-1575.

13. Ediger, D., Önal, B.B., Ege, E. (2008). Astım ve rinit hastalarında tamamlayıcı ve alternatif tedavi kullanımı (The usage of complementary and alternative medicine in patients with asthma and rhinitis). Astım ve Alerji Immunoloji Dergisi 6: 61-65.

14. Erci, B. (2007). Attitudes towards holistic complementary and alternative medicine: a sample of healthy people in Turkey. Journal of Clinical Nursing 16: 761-768.

15. Ernst, E. (1998). Complementary therapies for asthma: what patients use. Journal of Asthma 35: 667-671.

16. Ernst, E. (1999). Complementary/alternative medicine for asthma: we do not know what we need to know. The Chest 115: 1-3.

17. Fouladbakhsh, J.M., Stommel, M. (2007). Using the behavioral model for complementary and alternative medicine: The CAM healthcare model. Journal of Complementary \& Integrative Medicine 4: 11.

18. George, J., Ioannides-Demos, L.L., Santamaria, N.M., Kong, D.C., Stewart, K. (2004). Use of complementary and alternative medicines by patients with chronic obstructive pulmonary disease. The Medical Journal of Australia 181: 248-251.

19. Helms, J.E. (2006). Complementary and alternative therapies: A new frontier for nursing education? Journal of Nursing Education 45: 117-123

20. Huntley, A., Ernst, E. (2000). Herbal medicines for asthma: a systemic review. Thorax 55: 925-929.

21. Janson, C., Chinn, S., Jarvis, D., Burney, P. (1997). Physician-diagnosed asthma and drug utilization in the European Community Respiratory Health Survey. European Respiratory Journal 10: 1795-1802.

22. Kav, T. (2009). Use of complementary and alternative medicine: A survey in Turkish gastroenterology patients. BMC Complementary and Alternative Medicine 9: 41.

23. Khalaf, A.J., Whitford, D.L. (2010). The use of complementary and alternative medicine by patients with diabetes mellitus in Bahrain: A cross-sectional study. BMC Complementary and Alternative Medicine 10: 35.

24. Kurt, E., Bavbek, S., Pasaoglu, G., Abadoglu, O., Misirligil, Z. (2004). Use of alternative medicines by allergic patients in Turkey. The Allergology and Immunopathology 32: 289-294.

25. Mao, J.J., Palmer, C.S., Healy, K.E., Desai, K., Amsterdam, J. (2011). Complementary and alternative medicine use among cancer survivors: A population-based study. Journal of Cancer Survivorship 5: 8-17.

26. Mazur, L.J., De Ybarrondo, L., Miller, J., Colarsudo, G. (2001). Use of alternative and complementary therapies for pediatric asthma. Texas Medical 97: 64-68.

27. Ng, T.P., Wong, M.L., Hong, C.Y., Koh, K.T.C., Goh, L.G. (2003). The use of complementary and alternative medicine by asthma patients. The Quarterly Journal of Medicine 96: 747-754.

28. Ogbera, A.O., Dada, O., Adeyeye, F., Jewo, P.I. (2010). Complementary and alternative medicine use in diabetes mellitus. West African Journal of Medicine 29: 158-162.

29. Oguz, S., Pinar, R. (2000). Tamamlayıcı tıp yöntemlerinden en fazla hangileri tercih ediliyor? I. International \& VII. National Nursing Congress Book, Antalya, Turkey, 358-360.

30. Orhan, F., Sekerel, B.E. (2002). Bronsial astım tedavisinde alternatif yöntemler (Alternative Therapies in bronchial asthma). Türkiye Klinikleri 4: 129-134.

31. Sidora-Arcoleo, K., Yoos, H.L., Mcmullen, A., Kitzman, H. (2007). Complementary and alternative medicine use in children with asthma: Prevalence and sociodemographic profile of users. Journal of Asthma 44: 169-175. 
32. Singer, L., Karakis, I., Ivri, L., Gross, M., Botolin, A., Gazala, A. (2007). The characteristics of complementary and alternative medicine use by parents of asthmatic children in Southern Israel. Acta Paediatrica 96: 1693-1697.

33. Shah, S.H, Engelhardt, R., Ovbiagele, B. (2008). Patterns of complementary and alternative medicine use among United States stroke survivors. Journal of Neurological Science 271: 180-185.

34. Slader, C.A., Reddel, H.K., Jenkins, C.R., Armour, C.L., Bsnic-Anticevich, S.Z. (2006). Complementary and alternative medicine use in asthma: who is using what?. Respirology 11: 373-387.

35. Tarhan, O., Alacacioglu, A., Somali, I. (2009). Complementaryalternative medicine among cancer patients in the western region of Turkey. Journal of The Balcan Union of Ongology 14: 265-269.

36. Tas, F., Ustuner, Z., Can, G. (2005). The prevalence and determinants of the use of complementary and alternative medicine in adult Turkish cancer patients. Acta Oncology 44: 161-167.

37. Yeh, GY., Davis, R.B., Phillips, R.S. (2006). Use of complementary therapies in patients with cardiovascular disease. The American Journal of Cardiology 98: 673-680.

38. Yildirim, Y., Tinar, S., Yorgun, S. (2006). The use of complementary and alternative medicine (CAM) therapies by Turkish women with gynecological cancer. European Journal of Gynaecologic Oncology 27: 81-85.

39. Zick, S.M., Blume, A., Aaronson, K.D. (2005). The prevalence and pattern of complementary and alternative supplement use in individuals with chronic heart failure. Journal of Cardiac Failure 11: 586-589.

40. Ziment, I., (2003). Complementary and alternative medicine therapies for chronic obstructive pulmonary disease. Focus on Alternative and Complementary Therapies 8: 385-391. 